\title{
Hipotireoidismo iatrogênico em eqüino decorrente de excesso de iodo: relato de caso
}

[Equine iatrogenic hypothyroidism due to iodine excess: case report]

\author{
R.G.S. Dória ${ }^{1}$, P.A. Canola $^{2}$, G. Ribeiro ${ }^{1}$, P.A. Di Filipo ${ }^{1}$, D.P.M. Dias ${ }^{1}$, C.A.A. Valadão ${ }^{3}$ \\ ${ }^{1}$ Aluna de pós-graduação - FCAV-UNESP - Jaboticabal, SP \\ ${ }^{2}$ Residente - FCAV-UNESP - Jaboticabal, SP \\ ${ }^{3}$ Faculdade de Ciências Agrárias e Veterinárias - UNESP - Jaboticabal, SP
}

\begin{abstract}
RESUMO
Relata-se o caso de um eqüino com sinais clínicos clássicos e avaliação hormonal compatível com hipotireoidismo primário, decorrente do uso sistêmico contínuo de iodeto de potássio, na dosagem de $60 \mathrm{~g} / \mathrm{dia}$. O tratamento consistiu na simples remoção da fonte de iodo, o que reduziu, gradualmente, as manifestações clínicas. Este relato de caso contribui com o estudo do hipotireoidismo iatrogênico em eqüinos adultos e, dessa forma, alerta para os possíveis efeitos colaterais indesejáveis de terapias à base de iodo.
\end{abstract}

Palavras-chave: eqüino, hipotireoidismo, excesso de iodo

\begin{abstract}
This report describes a case of an equine presenting classic clinical signs and hormonal profile related to primary hypothyroidism due to the continued systemic administration of 60g/day of potassium iodate. Remission of the problem required the elimination of iodine source, which led to a gradual reduction in the clinical manifestation. This case report contribute with the iatrogenic hypothyroidism study in adult horses and warn veterinarians to the possible undesirable collateral effects of iodine therapies.
\end{abstract}

Keywords: horse, hypothyroidism, iodine excess

\section{INTRODUÇÃO}

A disfunção na glândula tireóide, em eqüinos, é uma anormalidade endócrina incomum e pouco compreendida, que tem sido associada a várias desordens clínicas (Stanley e Hillidge, 1982; Messer, 1997). O hipotireoidismo é geralmente primário, associado com enfermidade da glândula tireóide, ou secundário, resultante da secreção inadequada de hormônio estimulador da tireóide pela glândula pituitária (Stanley e Hillidge, 1982). O excesso de iodo, bem como sua deficiência, pode provocar disfunção da tireóide e interferir nos testes da glândula. Compostos exógenos que contenham iodo ou iodeto são de particular interesse. Os indivíduos podem responder a quantidades excessivas de iodo suprimindo ou acelerando a produção de hormônio. A intoxicação pelo iodo, ou iodismo, raramente é relatada nos eqüinos (Duckett, 2000). Quando ocorre, é mais provável que a administração iatrogênica de substâncias que contenham iodo, seja a causa (Schmitz, 2000). Nagataki (1974) sugeriu que esse efeito depende não apenas da quantidade e tempo de exposição ao iodo, mas também do estado funcional da glândula tireóide e do potencial genético individual e da espécie. Assim, na maioria dos animais domésticos, existe uma ampla margem de segurança entre a necessidade de iodo requerida e o nível máximo tolerado, exceto para eqüinos. $\mathrm{O}$ nível máximo tolerável para eqüinos tem sido estimado em $5 \mathrm{ppm}$. Cavalos têm uma elevada sensitividade pelo iodo, recomenda-se, então, 3 a $5 \mu \mathrm{g} / \mathrm{kg} /$ peso corporal $/$ dia. Uma dosagem de $35 \mathrm{mg} /$ dia pode causar severos riscos à saúde, leva ao aumento da tireóide e à redução dos valores de T3 e T4 (Wehr et al., 2002).

Recebido em 17 de outubro de 2007

Aceito em 30 de maio de 2008

E-mail: redoria@uol.com.br 
Em eqüinos adultos, o hipotireoidismo tem sido associado a sinais clínicos como alopecia, anidrose, episódios de rabdomiólise e intolerância ao exercício. Não se comprovou, ainda, se o hipotireoidismo é uma causa ou um fator contribuinte na laminite (Schmitz, 2000). Outros relatos incluem o bócio secundário resultante da ingestão excessiva de iodo, de secreções aumentadas do trato respiratório, de corrimento nasal, de tosse não produtiva intermitente, de lacrimejamento excessivo. Anemia de baixo grau, hipotermia, bradicardia, obesidade e letargia foram verificadas em éguas cuja função da tireóide apresentava supressão, em virtude da ingestão excessiva de iodo.

O diagnóstico do hipotireoidismo iatrogênico baseia-se em histórico recente de exposição a elevados níveis de iodo por tempo prolongado, associado a sinais clínicos compatíveis. A maioria dos casos de disfunção da tireóide é diagnosticada com base na simples detecção de baixos níveis de T4 ou T3 no soro de animais em repouso (Messer, 1997), porém esta forma de avaliação deve ser cautelosa (Sojka et al., 1993).

O hipotireoidismo em eqüinos adultos, ao contrário do que ocorre em potros, não representa risco para a vida (Duckett, 2000). O tratamento consiste na simples remoção da fonte de iodo. Como o elemento é rapidamente mobilizado e excretado dos tecidos, os sinais clínicos, geralmente, desaparecem de forma razoavelmente rápida, quando o excesso de iodo é removido (Schmitz, 2000).

Em eqüinos, poucos são os relatos de casos e não foi encontrado trabalho científico publicado que demonstre o hipotireoidismo iatrogênico, decorrente do excesso de iodo. Dessa forma, este trabalho busca contribuir com mais um relato de caso, em que o uso excessivo de medicamento à base de iodo, em eqüino adulto, causou alterações físicas, clínicas, comportamentais e hormonais compatíveis com um quadro de hipotireoidismo.

\section{CASUÍSTICA}

Um cavalo, sem raça definida, 450kg, 14 anos, foi encaminhado ao Hospital Veterinário da Faculdade de Ciências Agrárias e Veterinárias UNESP, devido a feridas granulomatosas, com secreção abundante, na região distal dos membros torácicos. Foi realizada ressecção cirúrgica e biópsia do tecido granulomatoso. A avaliação histopatológica revelou necrose extensa de tecido epitelial, associado a um marcante afluxo inflamatório de neutrófilos, edema perivascular e várias áreas extremamente eosinofílicas, e, perifericamente, foram encontradas hifas fúngicas, laudo compatível com a enfermidade pitiose cutânea eqüina. $\mathrm{O}$ tratamento principal instituído foi $60 \mathrm{~g}$ de iodeto de potássio, diariamente, por via oral, iniciado no mesmo dia da cirurgia. Treze dias após início da terapia sistêmica, o animal começou a apresentar edema da porção ventral torácica e abdominal, edema de prepúcio e edema de membros pélvicos, principalmente na articulação tibiotarsometatársica, os quais evoluíram progressivamente com o passar dos dias. Também, foi observado lacrimejamento abundante, secreção nasal seromucóide e salivação excessiva. $\mathrm{O}$ animal manifestava progressiva apatia, apetite seletivo e permanecia estático no piquete gramado, relutando em caminhar, sendo que, toda a musculatura dos membros pélvicos apresentava-se contraída. Também, notou-se descamação da pele, principalmente na região das orelhas, perda de brilho e queda dos pêlos (Fig. 1). O animal apresentava sudorese abundante, redução de motilidade intestinal e hipertermia $\left(39,8^{\circ} \mathrm{C}\right)$. O caráter progressivo do quadro foi evidente e não foi observado aumento da glândula tireóide. A medicação com iodeto de potássio só foi suspensa quando o animal apresentou-se completamente apático, anoréxico e sem motilidade intestinal. Nesse dia, foi realizada coleta de sangue para confirmar a suspeita clínica de hipotireoidismo. O resultado do teste de quimioluminescência ${ }^{1}$ revelou que a concentração de T4 $(0,10 \mu \mathrm{g} / \mathrm{dl})$ estava abaixo dos valores de referência para eqüinos (2,5 a $4,5 \mu \mathrm{g} / \mathrm{dl})$.

Após 24 horas sem medicação com iodeto de potássio, o animal, gradativamente, apresentouse alerta ao ambiente, alimentou-se e apresentou motilidade intestinal. Com o passar dos dias, todos os sinais regrediram por completo.

${ }^{1}$ Instituto Hermes Pardini - Belo Horizonte, Brasil. 


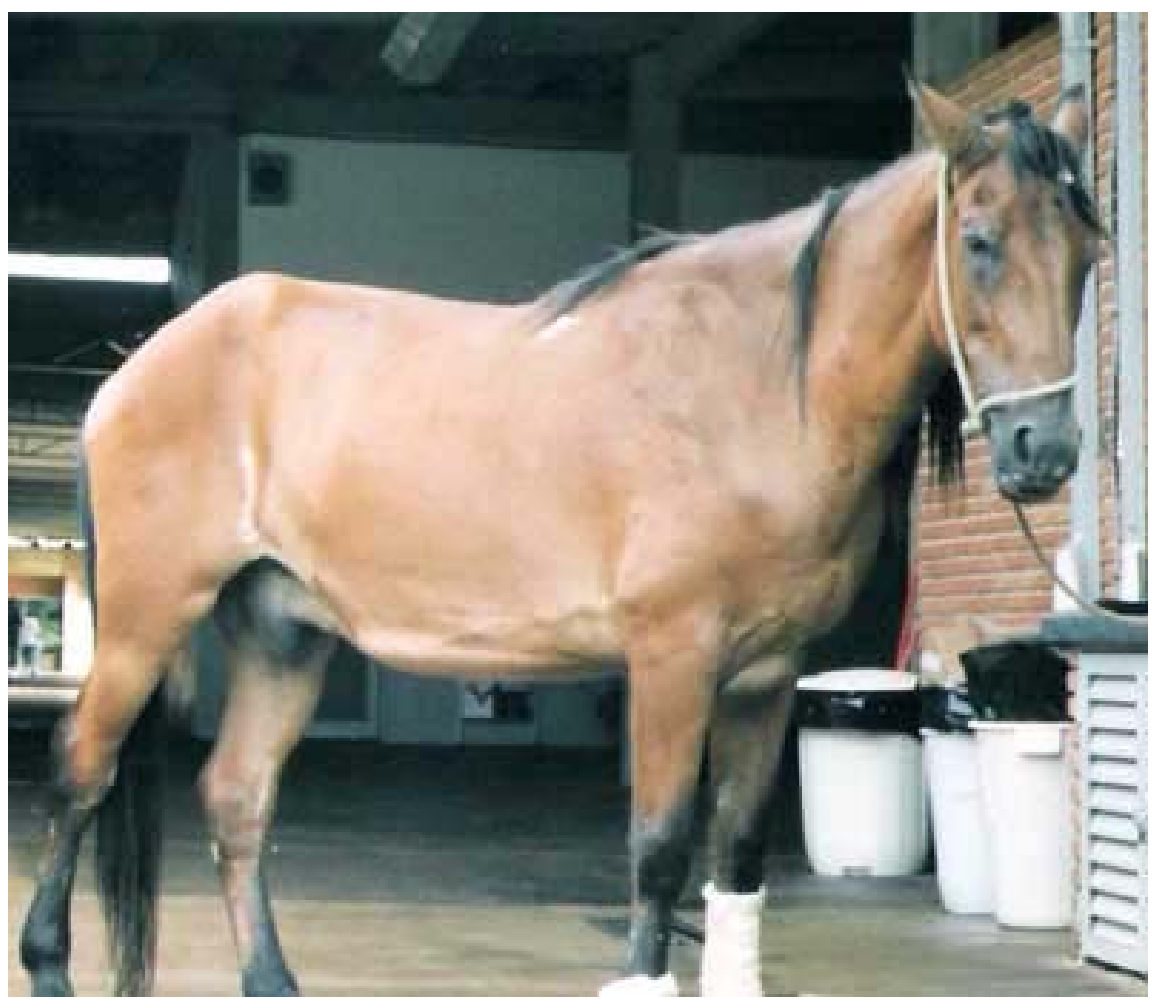

Figura 1. Eqüino apresentando sinais sugestivos de hipotireoidismo como apatia, edema ventral de abdômen e de prepúcio, descamação de pele na região da orelha e perda de pêlos na região dos olhos, após tratamento sistêmico com iodeto de potássio $(60 \mathrm{~g} / \mathrm{dia})$.

\section{DISCUSSÃO}

A disfunção primária da glândula tireóide forma mais freqüente de hipotireoidismo em eqüinos, pode ser provocada, como demonstrado neste caso, de forma iatrogênica, por meio de uso prolongado de medicações sistêmicas à base de iodo no tratamento de diversas afecções (Duckett, 2000; Mazan, 2005).

O suplemento de iodo é importante na função da tireóide, mas, em excesso, pode bloquear as características funcionais e desencadear alteração na atividade tireodiana. Dependendo da dose de iodo e das condições prévias da glândula, o excesso de iodo pode promover o hipotireoidismo ao induzir o bloqueio da biossíntese ou ao causar problemas na secreção dos hormônios tireoideanos (Castillo et al., 2003).

Neste caso, foi comprovado um quadro de hipotireoidismo iatrogênico, decorrente do excesso de iodo, uma vez que o valor de T4 sérico encontrava-se 25 a 45 vezes inferior aos valores de T4 considerados normais para eqüinos (Schmitz, 2000; Beyer, 2005). Ressalta-se que na interpretação dos valores de T4, devem ser consideradas as possíveis influências de eventos fisiológicos, patofisiológicos e farmacológicos.

Associado ao valor sérico de $\mathrm{T} 4$, os sinais clínicos evidenciados neste estudo estão de acordo com as descrições de Sojka et al. (1993) e Duckett (2000), que ao induzirem, experimentalmente, hipotireoidismo em cavalos, observaram apatia, apetite reduzido, letargia, edema dos membros posteriores e pelagem espessa.

Assim, até que mais pesquisas sejam realizadas e melhores testes sejam desenvolvidos, os diagnósticos devem ser baseados na combinação de um histórico bem feito, de sinais físicos, de testes laboratoriais e de diagnósticos diferenciais com a doença de Cushing eqüina e a síndrome metabólica eqüina (Breuhaus, 2004; Beyer, 2005; Mazan, 2005). 
Segundo Mazan (2005), em cavalos adultos, o hipotireoidismo não deve ser tratado com medicamentos. A remissão dos sinais/sintomas clínicos requer apenas a eliminação da fonte de iodo, pois, com o decréscimo gradual dos níveis corpóreos de iodo, ocorrerá redução nas manifestações da toxicose (Schmitz, 2000; Paulikova et al., 2002). Este fato foi confirmado neste caso, em que se verificou a regressão de todas as alterações físicas, clínicas e comportamentais após a retirada da terapia com iodeto de potássio.

Embora sejam clássicos os sinais clínicos de hipotireoidismo em eqüinos, trabalhos científicos que abordem essa afecção são escassos (Breuhaus, 2004; Beyer, 2005).

Este relato ressalta a necessidade de cautela ao se prescrever tratamentos para eqüinos, com produtos à base de iodo, para serem realizados nas propriedades, sem acompanhamento veterinário, de forma a evitar efeitos colaterais indesejáveis, como o hipotireoidismo iatrogênico.

\section{REFERÊNCIAS BIBLIOGRÁFICAS}

BEYER, M. Hypothyroidism - misdiagnosed and misunderstood. Horses and Horse Information, 2005. Disponível em: <http://www.horses-andhorseinformation.com/articles/0496hypo.shtlm>. Acessado em: 07 jun. 2005.

BREUHAUS, B.A. Review of thyroid function and dysfunction in adult horses. In: ANNUAL CONVENTION OF THE AMERICAN ASSOCIATION OF EQUINE PRACTITONERS, 50., 2004, Denver. Proceedings... Denver, 2004. p.334337.
CASTILLO, V.A.; RODRIGUEZ, M.S.; LALIA, J.C. et al. Morphologic changes in the thyroid glands of puppies fed a high-iodine commercial diet. Apopka: International Journal of Applied Research in Veterinary Medicine, v.1, n.1, 2003. Disponível em: $<\mathrm{http} / / /$ www.jarvm.com/articles/Vol1Iss1/CASTIJVM .htm>. Acessado em: 07 jun. 2005.

DUCKETT, W.M. Tireóide. In: REED, S.M.; BAYLY, W.M. (Eds). Medicina interna eqüina. Rio de Janeiro: Guanabara Koogan, 2000. p.784-792.

MAZAN, M. Hypothyroidism in horses, 2005. PetPlace.com, 2005. Disponível em: $<\mathrm{http} / / / \mathrm{www}$.petplace.com/articles/artshow.asp?artID= 3724>. Acessado em: 30 jun. 2005.

MESSER IV, N.T. Thyroid disease (dysfunction). In: ROBINSON, N.E. (Ed). Current therapy in equine medicine. 4.ed. Philadelphia: W. B. Sauders, 1997. p.502-503.

NAGATAKI, M.S. Effect of excess quantities of iodide. In: GREER, M.A.; SALOMON, D.H. (Eds). Handbook of physiology. Washington: Thyroid. Am. Physiol. Soc., 1974. v.3, p.165-172.

PAULIKOVA, I.; KOVAC, G.; BIRES, J. et al. Iodine toxicity in ruminants. Vet. Med. - Czech., v.47, p.343350, 2002.

SCHMITZ, D.G. Problemas toxicológicos. In: REED, S.M.; BAYLY, W.M. (Eds). Medicina interna eqüina. Rio de Janeiro: Guanabara Koogan, 2000. p. 877.

SOJKA, J.E.; JOHNSON, M.A.; BOTTOMS, G.D. Serum triiodothyronine, total thyroxine, and free thyroxine concentrations in horse. Am. J. Vet. Res., v.54, p.52-55, 1993.

STANLEY, O.; HILLIDGE, C.J. Alopecia associated with hypothyroidism in a horse. Equine Vet. J., v.14, p.165-167, 1982.

WEHR, U.; ENGLSCHALK, B.; KIENZLE, E. et al. Iodine imbalance in relation to iodine intake in ponies. J. Nutr. v.132, suppl., p.1767S-1768S, 2002. 